\title{
Apert Syndrome: A Rare Genetic Disorder
}

\author{
M Hassan ${ }^{1}$, B H N Yasmeen ${ }^{2}$, M Khan ${ }^{3}$, A Mukti ${ }^{4}$
}

Abstract

Apert syndrome is a rare type I acrocephalosyndactyly syndrome having autosomal dominant inheritance due to mutations in the fibroblast growth factor receptors gene. New or fresh mutations are also frequent. It is characterized by dysmorphic face, craniosynostosis, severe syndactyly of the hands and feet. Apert syndrome affects the first branchial or pharyngeal arch, the precursor of the maxilla and mandible. Disturbances in the development of branchial arches during fetal period create extensive malformation in different parts of the body. Management of Apert syndrome requires a multidisciplinary approach. We, hereby, report a case of a 45-days old baby with Apert syndrome.

Key words : Acrocephalosyndactyly, apert syndrome, craniosynostosis, syndactyly

DOI: https://doi.org/10.3329/nimcj.v11i2.54066

Northern International Medical College Journal Vol. 11 No. 2 January 2020, Page 475-477

1 Prof. Dr. Mahmuda Hassan

Professor

Dept. of Paediatrics

Ad-din Women's Medical College Dhaka

${ }^{2}$ Prof. Dr. B H Nazma Yasmeen

Professor and Head

Dept. of Paediatrics

Northern International Medical

College, Dhaka

3 Dr. Masuma Khan

Assistant Professor

Dept. of Paediatrics

Ad-din Women's Medical College

Dhaka

4

Dr. Afsana Mukti

Assistant Professor

Dept. of pediatrics

Ad-din Women's Medical College Dhaka

Correspondence

Prof. Dr. Mahmuda Hassan

Professor

Dept. of Paediatrics

Ad-din Women's Medical College

Dhaka

e-mail: mahmudahasn@yahoo.com

\section{Introduction}

Apert syndrome is a rare type I acrocephalosyndactyly syndrome which was first described by Eugene Apert, a French physician, in $1906 .{ }^{1}$ It is characterized by craniosynostosis, severe syndactyly of the hands and feet, and dysmorphic facial features. ${ }^{1,2}$ The incidence of Apert syndrome is approximately 1 in 50,000 to 80,000 live births. $^{3}$

Diagnosis of this syndrome can be done at birth by assessing the physical appearance of the baby. Investigations including radiographs, magnetic resonance imaging (MRI), genetic testing, X-rays and $\mathrm{CT}$ scans can be used to confirm the diagnosis. In our context only $X$ rays and/or CT scans of the skull may be done to accurately diagnose the condition. MRI, genetic testing is not available everywhere and not also affordable for many of us.

\section{Case report}

A 45-days old baby boy was admitted in the Paediatrics department of Ad-din Women's Medical College Hospital, Dhaka, with a history of cough and cold for 5 days and fever with respiratory distress for 2 days. His parents were very worried about the symmetric syndactyly of both hands and feet of their child. His antenatal period was uneventful.There was no history of taking any medicine or exposure to any infection of the mother during the antenatal period. He was born by normal vaginal delivery at term in a hospital. There was also no significant postnatal history. He was the first issue of a nonconsanguineous parents. Both the parents were healthy and in third decade of life. No family history of similar problem or any other congenital abnormality was reported.

On admission, he was active and alert. His weight was $3.1 \mathrm{~kg}$, length was $52 \mathrm{~cm}$. He had brachycephaly with head circumference of $30 \mathrm{~cm}$, flat occiput, had prominent forehead, anterior fontanelle was wide with sutural diasthesis involving sagittal and mitopic sutures. Coronal suture was fussed with ridging. The mid-face was hypoplastic and there was also pinched nose, downward slanting of palpebral fissures and trapezoid mouth. Intra-orally cleft palate with deficient premaxilla, $\mathrm{V}$-shaped maxillary arch were found. He had syndactyly, hands appear spoon-shaped, characterized by fusion of all the fingers. In both feet all toes fused giving it a club-like feature.

During admission his temperature was $102^{\circ} \mathrm{F}$, respiratory rate was 62 breaths per minute.Vesicular breath sound with bilateral rhonchi with crepitation was detected on auscultation. With all above findings we provisionally diagnosed the patient as a case of Apert syndrome with pneumonia.

Complete blood count (CBC), C-reactive protein level (CRP) and X-ray chest were done. Results of all these investigations favoured the diagnosis 
of pneumonia.Only injectable Amoxicillin was given for his treatment. Oxygen was given SOS. Expressed breast milk was given through N/G tube until respiratory distress was subsided. After 5 days of treatment, patient's condition was improved, and we discharged the patient with the advice of further management.

During discharge, we counseled the parents about Apert syndrome. The patient had complex combination of multiple deformities. Various multidisciplinary surgical interventions would be required for correction of facial dysmorphisms and syndactyly of his hands and feet. Therefore, we referred the baby to the Paediatric Surgery department, and the Plastic surgery department of Dhaka Medical college hospital, Dhaka as well as to the Maxillofacial and orthodontics surgery department of Dhaka Dental College Hospital, Dhaka. Finally, we reassure the parents that with proper treatment in early life, Apert syndrome has good outcome in both intelligence and appealing appearance in adult life.

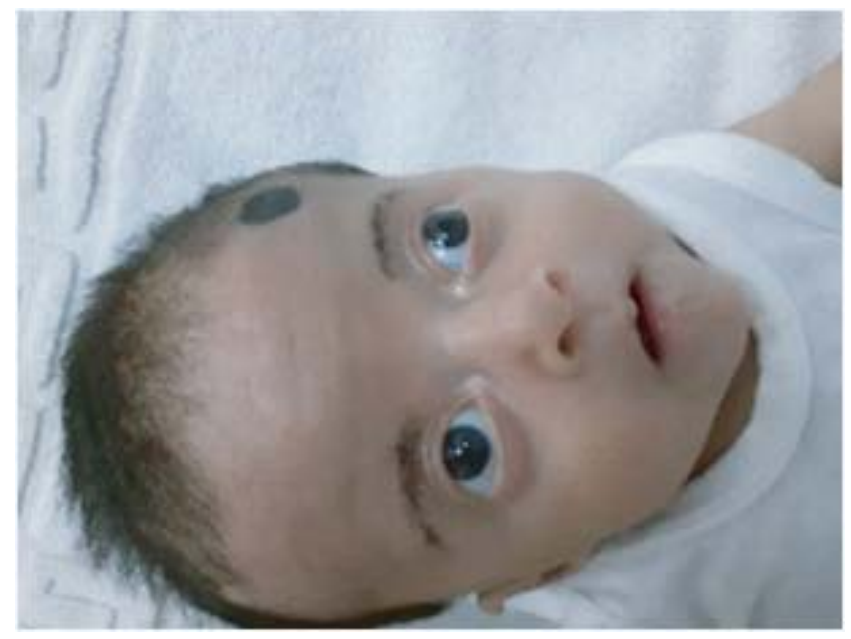

Fig 1: face of the baby, depressed nose and trapezoid mouth

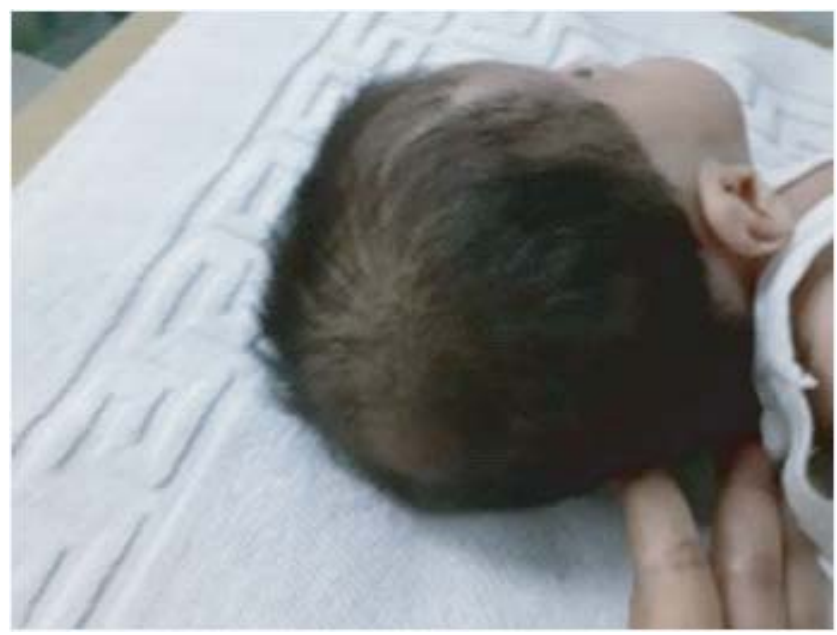

Fig 2: Flat occiput with shortened antero-posterior diameter

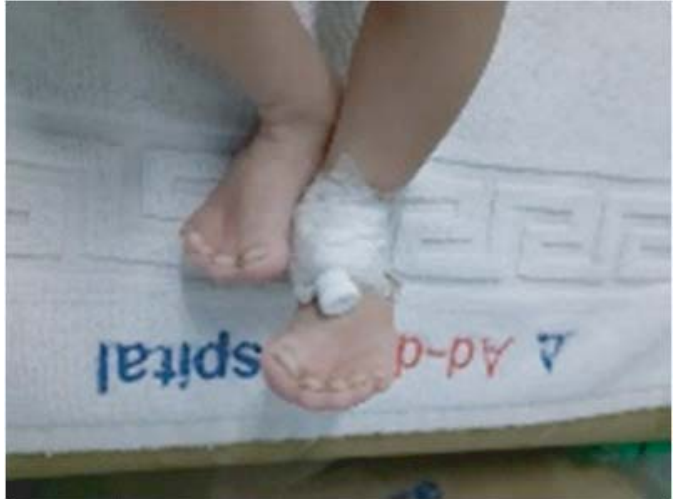

Fig 3 : Syndactyly involving feet

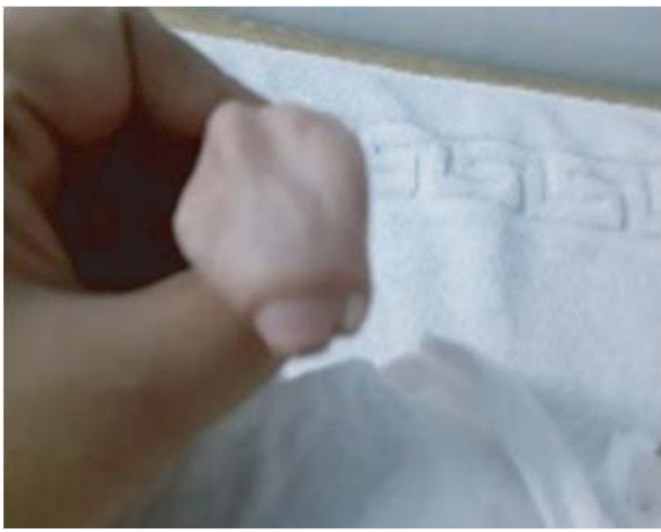

Fig 4: hand, single nail over the matted finger

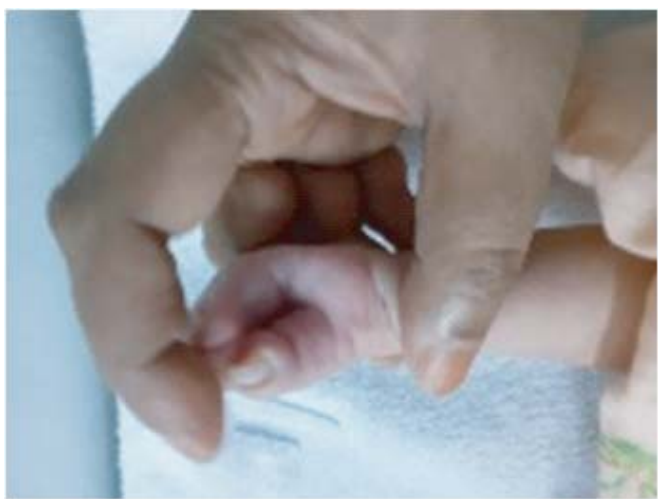

Fig 5: Syndactyly of hand, spade like hands

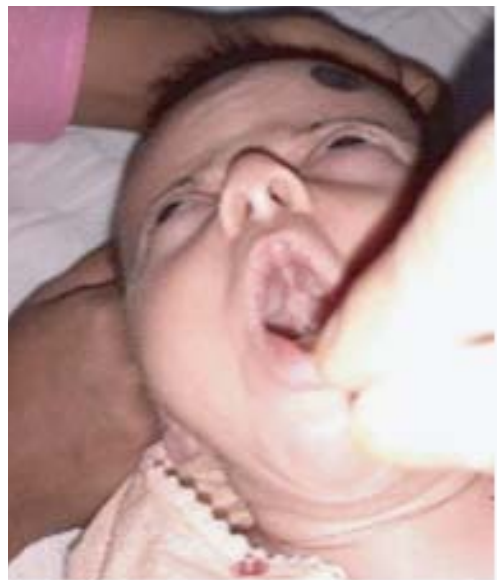

Fig 6: Small Cleft palate with deficient premaxilla, V-shaped maxillary arch 


\section{Discussion}

The rare clinical abnormality, Apert syndrome must be differentiated from other craniofacial syndromes such as carpenter syndrome, Crouzon syndrome and Pfeiffer syndrome. Carpenter syndrome, is an extremely rare, type II acrocephalosyndactyly syndrome, having autosomal recessive inheritance. It is characterized by a pointed, cone-shaped, or short, broad head with presence of extra or fused digits. ${ }^{4,5}$

Crouzon syndrome is also a rare genetic disorder having autosomal dominant inheritance. It is characterized by craniosynostosis which may presented as brachycephaly, turricephaly, frontal bossing, plagiocephaly etc.Hypoplastic maxilla, mandibular prognathism gives the characteristic facial appearance. Exophthalmos, hypertelorism are also common features. ${ }^{6}$ About $30 \%$ of patient develop hydrocephalus. ${ }^{7}$

Pfeiffer syndrome, a rare genetic disorder is also characterized by the craniosynostosis and presented with high prominent forehead, proptosis, hypertelorism maxillary hypoplasia.Thumbs and great toes are deviated from the other digits. Syndactyly may be present. Hearing loss is present in more than $50 \%$ patient. $^{8}$

Specific characteristic features differentiate these syndromes from each other.

The clinical features of Apert syndrome are distinctive. In skull coronal suture fuses prematurely before 3 months, leading to an acrocephalic head with shortened antero-posterior diameter, and a high prominent forehead. The mid-face is hypoplastic. Ocular anomalies include hypertelorism, proptosis, downward slanting palpebral fissures. The nose is short and wide with depressed nasal bridge. ${ }^{9-11}$ Craniofacial findings of the Apert syndrome include closed coronal suture during birth and the presence of a large anterior fontanel with metopic suture, which was present in this case. Cone-shaped head with shortened antero-posterior diameter, and a high prominent forehead, temporal regions appear protruding, while the occiput is flattened, same as this case (Figure 1,2).

The oral cavity of Apert syndrome patients is also characteristic. The clinical findings include a reduction in the size of the maxilla which may result in tooth crowding and an anterior open bite of the maxilla. The mandible is within normal size and shape and simulates a pseudo prognathism. ${ }^{11-12}$ Intra-orally maxillary arch is high, and $\mathrm{V}$ shaped, sagittal narrow palate also seen with lateral palatal swellings with prominent central fissure and mostly presents with a pseudo palate, as seen in this case (figure 6).

Dental anomalies such as impacted teeth, dental crowding, delayed eruption, ectopic eruption, supernumerary teeth, and thick gingiva are also common feature as child grows up. ${ }^{6,7}$
There may be cleft soft palate, byzantine-arch palate, choanal stenosis, and anomalies of the tracheal cartilage. ${ }^{1}$ Mouth breathing, observed in most cases of Apert syndrome. ${ }^{13}$

Syndactyly involving partial to complete fusion of the digits results in a spoon-like deformity of the hands and feet. ${ }^{1,2}$ In this case severe syndactyly of the hands and feet are present (figure 3,4,5).

Anomalies of the viscera,elbows and shoulders, skeleton and central nervous system may present with impaired mental function. ${ }^{9,10}$ But in this case no other associated congenital anomalies were found.

\section{Conclusion}

Apert syndrome usually diagnose at birth by the characteristic physical appearance of the baby. With all the characteristic findings present in our patient we finally diagnosed him as a case of Apert syndrome with pneumonia.

\section{Conflict of interest}

None

\section{References}

1. De Giovanni $\mathrm{CV}$, Jong C,WoollonsA.Whatsyndrome is this? Apert syndrome. Pediatr1. Dermatol 2007; 24:186-8.

2. Freiman A, Tessler O, Barankin B. Apert syndrome. Int J Dermatol 2006; 45:1341-3.

3. Rebelo N, Duarte R, Costa MJ, Leal MJ. Acrocephalosyndactyly-the coalesced hand. Eur J PediatrSurg 2002; 12:49-55.

4. Online Mendelian Inheritance in Man (OMIM): 201000

5. PerlynCa, Marsh Jl. Craniofacial dysmorphology of Carpenter syndrome: lessons from three affectedsiblings. Plasticand Reconstructive Surgery. March 1909.121 (3):97181. doi:10.1097/01.prs.0000299284.92862.6c. PMID 18317146

6. Crouzon syndrome. rarediseases.info.nih.gov.US:Genetic and Rare Diseases Information Center (GARD), National Institutes of Health. Retrieved 21 November 2018.

7. Casey Theresa, Selva Dinesh, Anderson, Peter J. Ophthalmic sequelae of Crouzonsyndrome. Ophthalmology. 2005.112 (6):11291134. doi:10.1016/ j.ophtha.2004.12.037. PMID 15885794

8. Pfeiffer syndrome. U.S. National Library of Medicine. Retrieved 2020-10-29.

9. Surman TL, Logan RM, Townsend GC, Anderson PJ. Oral features in Apert syndrome: a 5. histological investigation. OrthodCraniofac Res 2010; 13:61-7.

10. Carneiro GV, Farias JG, Santos FA, Lamberti PL Apert syndrome: review and report a case. 6. Braz J Otorhinolaryngol 2008;74:640.

11. Albuquerque MAP, Cavalcanti MGP. Computed tomography assessment of Apert syndrome. 7. Braz Oral Res 2004;18:35-9.

12. Verma S, Draznin M. Apert syndrome. Dermatol Online J 2005; 11:15.

13. Letra $A$, de Almeida $A L$, Kaizer $R$, Esper LA, Sgarbosa S, Granjeiro JM. Intraoral features 3. of Apert's syndrome. Oral Surg Oral Med Oral Pathol Oral RadiolEndod 2007; 103: e38-41. 